\title{
Stage I Prostate Cancer AJCC v7
}

National Cancer Institute

\section{Source}

National Cancer Institute. Stage I Prostate Cancer A/CC v7. NCI Thesaurus. Code C89232.

Stage I includes: (T1a-c, N0, M0, PSA less than 10, Gleason equal or less than 6); (T2a, NO, M0, PSA less than 10, Gleason equal or less than 6); (T1-2a, N0, M0, PSA X, Gleason X). T1a: Tumor incidental histologic finding in $5 \%$ or less of tissue resected. T1 b: Tumor incidental histologic finding in more than $5 \%$ of tissue resected. T1c: Tumor identified by needle biopsy (e.g., because of elevated PSA). T2a: Tumor involves one-half of one lobe or less. cN0: No regional lymph node metastasis. pN0: No positive regional nodes. M0: No distant metastasis. Gleason Equal or Less than 6: Well differentiated (slight anaplasia). Gleason X: Gleason score cannot be processed. (AJCC 7th ed.) 